\title{
The quantification of urban litter load at gross pollutant trap along Sungai Batu, Selangor
}

\begin{abstract}
The massive amount of urban litter in Malaysia is influenced by rapid population growth, development, economic growth and unsustainable lifestyles. Few studies have assessed the amount of urban litter load and its composition at gross pollutant trap (GPT), significantly contributing to lack of historical data. This study is aimed to assess the amount of urban litter load in wet basis condition at individual GPTs along Sungai Batu, Selangor in 2015. The urban litter collection data at each GPT in 2015 were sourced from Department of Irrigation and Drainage (DID). Samples were manually collected once a month, stored in plastic bag and immediately weighed and recorded by following the ASCE standard method. The result shows that the total amount of urban litter load in 2015 was $3761.72 \mathrm{~kg} /$ year (Mean $\pm \mathrm{SD}$; $313.4767 \pm 141.9105 \mathrm{~kg} /$ year). In such situations, further study on urban litter load and its composition trapped at GPTs is urgently required as it is crucial to establish baseline data information during the decision making process, holistically improving storm water management and urban litter management in Malaysia.
\end{abstract}

Keyword: Downstream defender; Drainage; Gross pollutant traps; Quantification; Urban litter 